\section{Your Choice Books}

\author{
Wendy Molyneux
}

\begin{abstract}
Author
Wendy Molyneux, is Service Development Officer for Warrington Library Museum and Archives Service and currently studying Library and Information Management at Manchester Metropolitan University. E-mail:wmolyneux@warrington.gov.uk
\end{abstract}

\begin{abstract}
During the summer of 2003, a three-month trial project, Your Choice Books, was undertaken on behalf of Warrington Library, Museum and Archives Service. A selection of existing library stock was relocated to the local YMCA, which is frequented by homeless people, in an attempt to combat social exclusion. Basic questionnaires were distributed to users of the YMCA and to members of library staff. This resulted in qualitative data determining interest in the programme from a sample of YMCA visitors and challenged staff to consider their social conscience with regards to those disadvantaged by homelessness. Quantitative data was obtained by tabulating responses using the statistical analysis package SPSS. The findings revealed this to be a successful project which, after careful consideration and discussion, is to continue indefinitely.
\end{abstract}

\section{The Occasion}

This article is based on the research report that was the winning entry for the Daphne Clark 2003 prize for practitioners.

\section{Acknowledgements}

The author is grateful to Martin Gaw, Head of Warrington Library, Museum and Archives Service for his continual support. Thanks to Sian Lambert at the Manchester Metropolitan University for her help and advice, Sue Blyth and Stephanie Hillier from Warrington YMCA and Warrington Borough Council's Policy and Research Department.

\section{Introduction}

Tackling social exclusion is one of Central Government's major priorities and, by the very nature of being a freely accessible gateway to leisure and information, libraries are generally viewed as a valuable public institution for the benefit of everyone in the community.

However, it could be questioned if this is truly the case as, "for many, public libraries continue to be associated with a white, middle class academic culture which alienates many disadvantaged people" (Department for Culture, Media and Sport, 2000) and, "at present,[libraries are] only superficially open to all .... and have service priorities and resourcing strategies which work in favour of existing library users rather than excluded or disadvantaged groups" (Muddiman, et al, 2000).

Much has been written about the issue of tackling social exclusion in general. However, less information associated with delivering public library services to those considered to be homeless, including asylum seekers and travellers, was available. This group of the community, it would appear, have until recently, been particularly marginalised.

Your Choice Books was the name given to a three month pilot project undertaken by Warrington Library Museum and Archives Service during the summer of 2003. The aim was to help create awareness amongst homeless people in the area of the educational, recreational and leisure benefits available to them thus challenging the ways libraries are perceived.

Utilising Warrington Central Library's stock, it focussed around reading material that was made available within a small collection housed at the YMCA in Warrington's town centre. Your Choice Books was aptly named as the items were selected, and exchanged every three weeks, by a small focus group including YMCA staff and regular drop-in visitors. The ultimate intention was not to provide isolated access to this collection, but to raise awareness of the facilities on offer within Warrington Libraries and encourage active membership. 
By establishing Your Choice Books, it was hoped to offer the opportunity for enjoyable reading experiences for disadvantaged people and help eliminate any feelings of community discrimination. Warrington Borough Council has entered a Public Service Agreement (PSA) with Central Government confirming their commitment to the vision of social inclusion. Warrington Libraries' part in this agreement is to promote the library service and encourage active usage in identified socially disadvantaged areas of the town. Any library visits, issue figures or newly registered borrowers resulting from the project were to be included in the PSA targets that need to be achieved by Warrington Libraries by the end of March 2005.

\section{Methodology}

Your Choice Books was conducted by means of an exploratory case study to examine "what is happening", to "seek new insights" and "generate ideas for future research" (Robson, 2002, p59). By using a flexible design strategy such as this, which "evolves during data collection" (Robson, 2002), it was felt that both quantitative and qualitative results would be produced. This would allow for a fuller picture of the interaction of factors and events in relation to library provision for the homeless to be obtained. The strategy for implementation was built around following the six point process outlined in Libraries for all, social inclusion in public libraries: policy guidance for local authorities in England, i.e., identifying the audience, assessing current practice, developing objectives, developing services, implementing those services and evaluating outcomes. (The Department for Culture, Media and Sport, 1999).

The suggested framework underpins the plan for this research methodology, enabling evidence to be collected in a variety of ways including observation, communication and contact. Identifying and establishing the views of the target study population and those involved in service delivery was critical to the project's success. In order to confirm requirements, access current practice and help develop how these needs could best be met, it was necessary to interact with the target group.
Primary data was obtained by participant observation by the project researcher and

Service Development Officer (does this sound like it is two different people?) through regular visits to the YMCA and by undertaking voluntary work at a local drop-in centre which is frequented by the homeless and those in need of emotional support. This allowed for interaction in activities and the questioning of staff and users. The project researcher was also invited to attend and participate in Warrington Borough Council's Homeless Strategy meetings and Anti-poverty and Social Exclusion Forum which assisted her in gaining an understanding of the problems of homelessness in the area. This approach proved to be extremely useful in collecting qualitative findings. By gaining familiarisation and recognising issues involved, relationships with staff and users were built and strengthened thus enabling a fuller understanding of happenings. Caution was taken to alleviate bias by accepting that individuals may change their behaviour during the observation period resulting in "distortion: what is observed does not represent .... normal behaviour" (Kumar, 1999, p.107)

Additional primary data was collected by the use of two separate questionnaires. It has been advised that

the value of the data is likely to be greatest where respondents provide answers that fit into a range of options offered by the researcher.

Denscombe (1998, p106)

Heeding this recommendation, basic structured questions were categorised offering multiple answers to help avoid ambiguity or misinterpretation.

The YMCA, located in Warrington's town centre, liases closely with Warrington Action for the Homeless. It acts as a key referral point for their first-base night shelter, having a regular clientele of visitors of all ages, gender, social and religious backgrounds. The first questionnaire was distributed by hand to visitors of the YMCA at the beginning of June 2003 over a two week period and included an outline of the project's purpose. It also attempted to 
ascertain the interest level for the scheme and provided an invitation to respondents to form part of a focus group responsible for choosing books for the library. With support and advice from Warrington Borough Council's Policy and Research Unit, given the transient nature of users, a random sample was undertaken. Although it was accepted that results produced may lack depth and detail, the intention was only to obtain an approximate representation of findings.

Staff at the YMCA raised the issue that some of the visitors to their premises had low literacy levels. It was hoped that findings would help identify anyone who appeared to have reading difficulties. The purpose for acquiring this information was to incorporate a partnership with the Millennium Volunteers, an agency who recruit the services of young people between the ages of sixteen to twenty-five for various volunteer work within the borough, to act as a 'reading buddy'.

The aim of the second questionnaire was to obtain the beliefs and attitudes of staff. It was felt staff's opinions of those of no fixed abode could possibly act as a barrier to access. Consequently, in order to comply as fully as possible with the vision of social inclusion, it was accepted that there may be a need to change library culture. It was assumed professional and front-line staff may have different views regarding the proposed alternative service delivery. To avoid bias, permanent staff at all levels and a random selection of library assistants who are employed on a casual basis were asked to complete a short, anonymous, open questionnaire. This resulted in both quantitative and qualitative findings helping to determine staffs' perspectives of those who are homeless or living in temporary accommodation.

To ensure the designs and presentations were clear and that questions were unambiguous, both questionnaires were piloted prior to distribution. The Youth and Community Worker and General Secretary for the YMCA piloted the YMCA questionnaire whilst the School and Community Librarian for Padgate Library, one of Warrington Libraries' satellites, agreed to pilot the staff questionnaire.

Responses were tabulated using the statistical analysis package SPSS yielding quantitative, numeric collections. Provision was also made on the questionnaires for respondents to add any comments they wished to make in order to obtain qualitative data. Additional qualitative data was provided by responses received after posting an email on a PLUSGeneral Listserver, a means by which syndicated libraries share information. Replies from this revealed some of the current practices and policies for the homeless from other authorities for comparison.

To complete the methodology, further data was collected by analysing documentary evidence obtained through Warrington Borough Council reports and plans.

\section{Respondents}

Community profiling presents a broad picture of Warrington as that of a fast growing, successful town having the second most prosperous economic profile of any town in England. However, closer inspection reveals this to mask wide variations in socio-economic positions placing some of the wards in Warrington amongst the most deprived 20\% in the country. Consequently, social inclusion strategies are high on the Council's corporate objectives acknowledging the importance of social inclusion and reinforcing their vision to develop services to those who are disadvantaged.

Warrington Libraries currently operate and support services for disadvantaged groups providing premises for a 'Talking Newspaper' project for the partially sighted and operating a housebound reader service. Your Choice Books attempted to widen access by addressing the barrier of library provision for homeless people in the community. Documentary sources provided information regarding homelessness services and various accommodations available in the area. The YMCA works in partnership with various agencies in the town including Social Services, the Community Health Council, Unemployment Forum, Women's Action Group 
and the Community Drugs Team offering advice and support to those in need, in addition to providing practical services for single homeless people. Its premises have been well established in the community for many years and, given its easily accessible position to Warrington Central Library, were identified as being a prime venue for the project.
Given the transient nature of those who are homeless, it was very difficult to determine the exact number of visitors. As a result a random survey of twenty people, chiefly male as shown in table 1, took part in the survey. It was felt by staff at the YMCA, results provided were representative of the study population.

\section{Table 1: Gender response}

\begin{tabular}{|l|l|l|}
\hline Gender & Frequency response & Percentage response \\
\hline Male & 17 & $85 \%$ \\
\hline Female & 3 & $15 \%$ \\
\hline
\end{tabular}

The YMCA welcomes visitors from multicultural backgrounds. However, at the time this survey was undertaken, those of white origin predominantly frequented the premises with all twenty respondents indicating this. Table 2 illustrates the majority were in the sixteen to forty-five age bracket, which again it was felt, was an acceptable representation.
However, on reflection, the questionnaire did not offer respondents the opportunity to indicate if they were over 60. Additionally, it appeared no replies were received from ethnic minorities. Both of these facts, may have affected the overall representation of respondents.

Table 2: Age of respondents

\begin{tabular}{|l|l|l|}
\hline Age & Frequency response & Percentage response \\
\hline $16-30$ & 8 & $40 \%$ \\
\hline $31-45$ & 9 & $45 \%$ \\
\hline $46-60$ & 3 & $15 \%$ \\
\hline
\end{tabular}

Libraries for all identified the importance of convincing library staff of the benefits of forward-thinking changes. Your Choice Books challenged employees to consider their views in terms of attitudes, values and beliefs by purposeful sampling of all permanent front-line members of staff, library managers and specialists in addition to random sampling of casual library assistants. A total of 70 questionnaires were distributed.

The request posted on PLUS asked how library authorities handled the process for registering those who are homeless and attempted to ascertain if projects similar to Your Choice Books were in place. However, this yielded a poor response rate. This brought into question whether library authorities had the homeless high on their list of priorities. This opinion was reflected by Muddiman, et al (2000) who reported that whilst some disadvantaged groups and individuals, eg. those with disabilities, the elderly and housebound were being considered at some level, , the same could not be said for other marginalised groups including travellers, refugees and homeless people. This latter group were considered by less than $20 \%$ of Public Library Authorities.

\section{Results}

Although the response from PLUS was disappointingly low, replies received were encouraging and revealed some interesting 
developments particularly in relation to joining procedures and borrowing access rights. There appeared to be a wide variation in policies ranging from limited access or a 'manager's discretion' clause through to an elimination of registration forms altogether. Investigation into previous and current library initiatives consulted for the literature review suggests that library authorities are, gradually, beginning to consider their current position within the community, and are looking at ways to challenge how they are perceived. Many are prepared to redesign their services as and when necessary to reflect the needs of all user groups. Examples included an "Access to Skills" project being run by Essex Library Service to support homeless people who are developing their ICT Skills, and reading development projects such as "Words without frontiers" targeting refugees and asylumseekers.

The catch-phrase theme of Your Choice Books was 'books for you - chosen by you'. As such, users of the YMCA joined the Youth and Community Worker and General Secretary, the Community Health Worker and a Millennium Volunteer in forming a focus group. All members of this group were proactive in creating and operating the project. This was directly in line with the recommendation set out in Libraries for all advising representatives will need to be involved in developing and establishing the service and monitoring its success. (Department for Culture, Media and Sport, 1999) At the onset, one visitor's enthusiasm soon became apparent when he echoed the feeling that, perhaps, one of the barriers to access for the homeless is their own self-perception, He stated

bringing the library to the YM would break down the feeling of intimidation which many people have after experiences with such as the Golden Square [a shopping mall in the town centre] who do not welcome many of us.

Initially, it appeared that many staff were reluctant to voice their opinions. This led to a considerable delay in receiving replies. For example, when asked why she had not yet done so, one library assistant commented she felt she should say one thing, but actually wanted to say another. After intervention from the Head of Service who reassured staff that their honest responses were required, and that they would not be judged, all except three questionnaires were returned. This was a $96 \%$ response rate. Nonetheless, results may have been distorted as staff may have felt under pressure to answer questions favourably.

As envisaged, managers and specialists appeared to have a more open view and were more amenable to allowing homeless people to register than front-line staff. However, table 3 illustrates that all staff more readily accept those in temporary accommodation.

Table 3: Percentage of respondents who feel a homeless person or one living in temporary accommodation should be allowed to join the library.

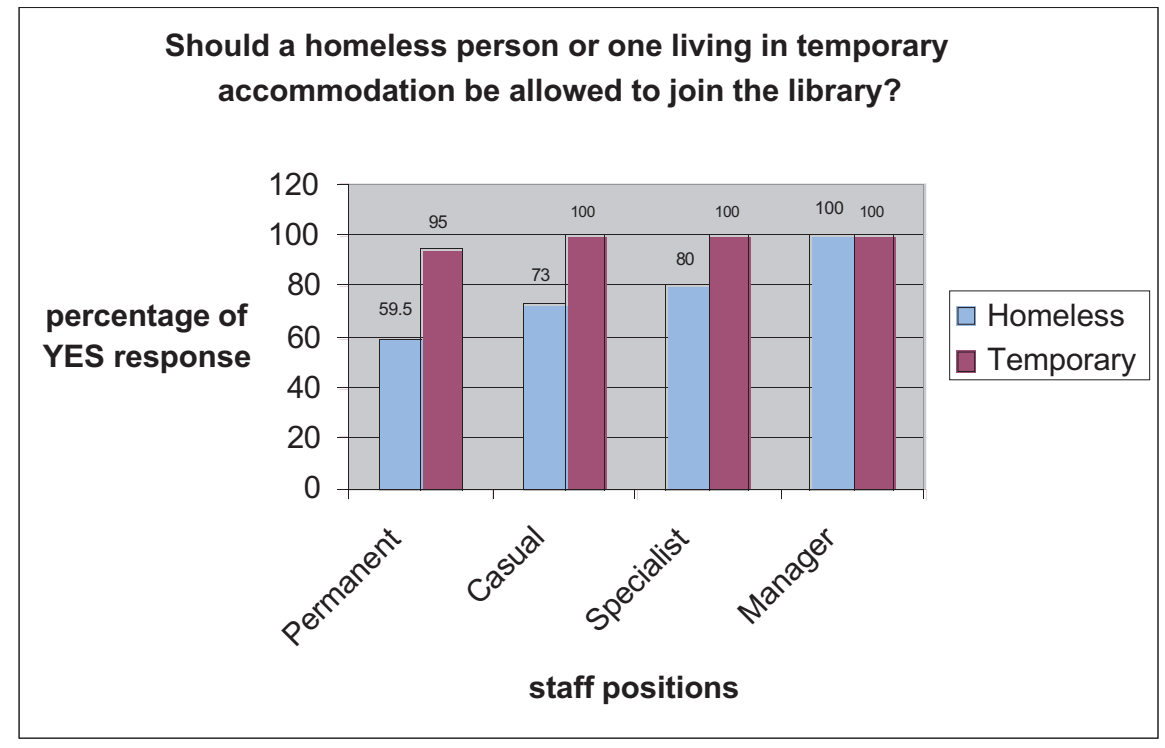


It was interesting to determine the level of membership staff felt homeless people and those living in temporary accommodation should be allowed. Comments ranged from encouraging ones such as

I do not think homeless people should be penalised because of their way of life which in many cases is a result of circumstances

through to the more negative view that a homeless person should not be allowed access to our stock, they should have free access to our discarded stock deposited at their drop in centres.

There appeared to be little concern amongst staff regarding the use of IT facilities by the homeless. However there was more concern surrounding the borrowing of stock items, particularly the loan of audio visual material as shown in table 4.

Table 4: Percentage of respondents who feel a homeless person should be allowed to borrow books/borrow audio visual/use IT?

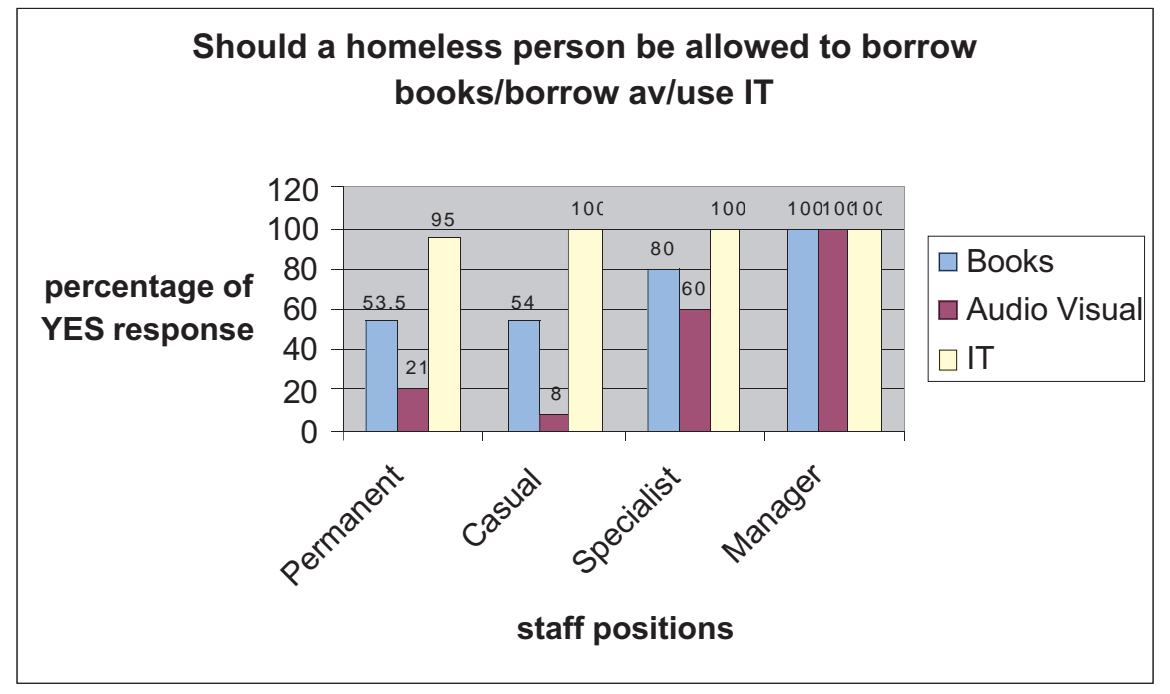

Staff at all levels were much more accepting of those living in temporary accommodation having fuller access although there still appeared to be some concern with loaning audio visual formats as reflected in table 5 .

Table 5: Percentage of respondents who feel a person in temporary accommodation should be allowed to borrow books/borrow audio visual/use IT

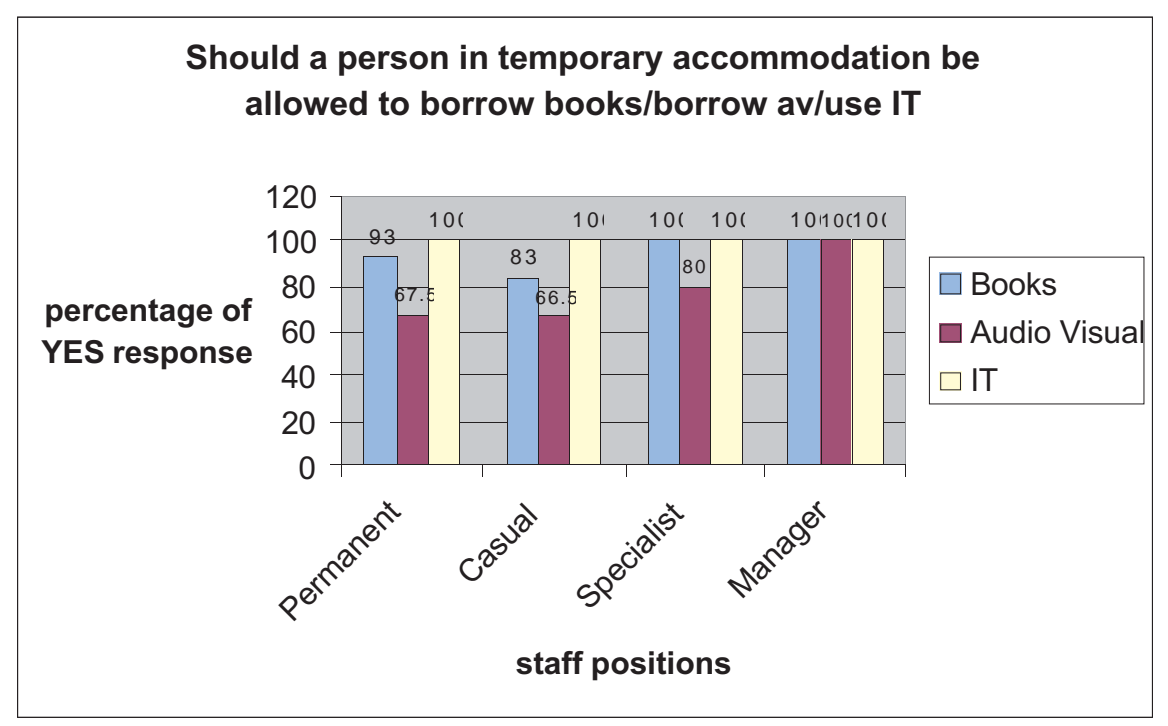


It was also noted that although most staff agreed in principle to allowing items to be borrowed, they sometimes preferred this to be on a restricted basis. This ranged from the loan of one item to twelve items. (Twelve is, currently the normal maximum loan for Warrington Libraries' members). Qualitative findings showed that phrases such as 'temporary' and 'recently' needed further clarification as such terms are subjective.

\section{Evaluating success and reviewing}

Statistical information revealed that several visitors to the YMCA eventually became registered library members making use of the range of services available. They thereby contributed to the collection of traditional performance indicators. However, it was felt these should not solely be used to measure the success of the project which was viewed holistically taking into account political, economic and social factors.

Politically, it was felt, the continuation of Your Choice Books would be directly in line with both Central and local government's vision of working towards a socially cohesive community. It would also meet guidelines set out by the Department for Culture, Media and Sport in Framework for the future and the Audit Commission report, Building better library services, which recommended that challenges and changes in service delivery be made and targeted at the needs of the community.

Economic sustainability is one of the major issues facing outreach projects. The secured Public Service Agreement provided the project's initial funding by allowing the employment of the Service Development post. As Your Choice Books relies on using existing library stock and is managed by the YMCA, with additional support from volunteers, it was felt there would be little direct cost implications for continuation. Regarding the concern of indirect financial costs in the way of stock losses, it was encouraging to discover there appeared to have been no damage to, or loss of, items loaned. Both of these factors provided proof that Your Choice Books was economically, a viable programme.

A young, female visitor who was very shy and withdrawn played a major contribution to the social aspect for continuation. Although hesitant at first, her interest in the project soon became apparent developing her into one of the strongest members of the focus group. Her enthusiasm and commitment prompted the Millennium Volunteer Project Co-ordinator to encourage her to become a volunteer herself to gain recognition for her work. She completed the necessary 200 hours voluntary work in record time receiving an award in addition to a special prize for her services and dedication. The confidence she gained from her experience inspired her to enrol on a Child Development course. I was pleased to report the success of this at Warrington Borough Council's Antipoverty and Social Exclusion Forum where it received a vote of confidence in Warrington Libraries and the project's continuation.

\section{Conclusion}

We currently have a Central Government who have placed social exclusion issues high on their list of priorities. The Department for Culture, Media and Sport and Audit Commission have identified ways in which library authorities can play their part in widening access for all including those who are disadvantaged. It would appear that the needs of some socially disadvantaged groups are being met by some library authorities. However, it could be argued, more consideration should be given to those who are literally homeless or living in temporary accommodation depriving them of services which are naturally open to the rest of the community.

Self perception and the institutional impression of libraries can act as barriers for those who are disadvantaged. Consequently, Warrington Libraries have acknowledged the importance for the need to redesign their library provision in order to address problems such as these. 
In an attempt to raise awareness of facilities on offer and the benefits of becoming an active member of the library service, a selection of Central Warrington Library's stock is now permanently co-located within the local YMCA which is frequented by homeless people and those in need of emotional support.

The logical framework outlined by the DCMS in their document, Libraries for all, provided the framework for a trial three month period. Survey questionnaires were distributed to users of the YMCA to determine the needs and views of the study population. In addition, library staff were challenged to question their social conscience by surveying their views regarding access to materials and services for those who are homeless or living in temporary accommodation.

At the end of the trial period, consideration for measuring success was given not only to traditional performance measurements indicators but also to the political, economic and social viability of continuing. The

overwhelming consensus was that of a successful venture with the decision to extend the provision indefinitely and, it was felt, that for library authorities to engage with hard to reach groups, they should consider establishing projects such as Your Choice Books.

\section{Future development}

"Case study results are specific to the particular context in which the study took place". (LeCompte and Goetz,1982, p107). Therefore, it is accepted Your Choice Books is an indicative project which may not be generalised.

Nonetheless, it satisfied its purpose by generating "ideas for future research" (Robson, 2002, p59).

Generally, much concern has been raised regarding the future of the library service, eg. 'lapsed users', declining issues, competition from bookstores, etc. By consulting with the public at outreach events, the author has been able to identify that members of the public are not using their local library for a variety of reasons. A strong example brought to the fore was the fact there are many families living in isolated areas, in deprivation with several children. Being at such a disadvantage often prevents easy opportunity for visiting the library, which is not high on the families' list of priorities. Spencer and Mathieson (2003) have argued that providing easy access by depositing collections where people are is the only way to ensure reluctant readers take time to look at reading material.

Considering these observations, to overcome difficulties such as these, following the success of Your Choice Books, Warrington Libraries are currently trialling another innovative project. Books $4 U$ is widening access to the public by taking books out in the community, providing collections in various venues where many people may frequent, such as doctor's surgeries and community houses, in socially disadvantaged areas of the Borough. The project is taking a radical approach by simply depositing items, without asking for responsibility to be taken from staff at the site. Members of the public are encouraged to borrow a book and return it to the collection or are invited to return it to one of three designated libraries where they can claim the loan of a free audio visual item. The ideal is, these 'taster' collections will encourage library visits. Once inside the building, awareness of the full range of facilities on offer will be raised consequently, increasing both new memberships and raising stock issues.

Books $4 U$ is being piloted until the end of March 2005 after which time, the feasibility of sustaining the project will be investigated. Early indication is that the scheme is being very well received by the community. One of Warrington Borough Council's Community Development Officers has praised the programme thus:

The young people I work with .... are some of the most disadvantaged young people in Warrington and are socially excluded from many activities. A large proportion .... are hard to engage in community activities and have a 
short attention span. However, to my surprise and delight these young people have been using the mini-library .... I felt I had to write to inform you that your project has succeeded by reaching these young people, many who have been let down by the education system and are out there with little or no support .... I see this as a major breakthrough ....

\section{References}

Denscombe, M. (1998) The good research guide for small scale social research projects, Maidenhead, Open University Press, ISBN 03352065 I 4

Department for culture, media and sport, (2000) Culture, media and sport -sixth report. URL: http//www.publications.parliament.uk/pa/cm 199900/cm select/cmcumeds/24I/24106.htm [accessed 28 April 2002]

Department for culture, media and sport, 1999. Libraries for all: social inclusion in public libraries: policy guidance for local authorities in England. London, DCMS

Kumar, R. (1999) Research methodology: a step-by-step guide for beginners. London, Sage,

ISBN 076|962I4x

Lecompte, M.D. and Goetz, J.P. (1982) Problems of reliability and validity in ethnographic research. Review of education research, 52, pp.3I-60. Cited by Robson, C. (2002) Real world research: a resource for social scientists and practioner-researchers, 2nd ed., Oxford, Blackwell, ISBN 063 |2/3058

Muddiman, D., et a. (2000) Open to all? the public library and social exclusion, vol. I: overview and conclusion. Library and Information Commission research report 84,

Wetherby, Resource, ISBN I 90239447x

Robson, C. (2002) Real world research: a resource for social scientists and practioner-researchers, $2^{\text {nd }}$ ed. Oxford, Blackwell. ISBN 063/2I3058

Spencer, J and Mathieson, J. (2003) Time for a change: co-operative reader development working in the North West of England. New library world. 104 (10), $391-403$ 